\title{
Teaching Note
}

\section{Persuasion Wars: Practicing social influence}

\author{
Peggy Sue Loroz \\ Gonzaga University, Spokane, WA, USA
}

\begin{abstract}
This article describes a series of learning activities called "Persuasion Wars." These in-class exercises use an active, collaborative learning approach in which student teams fight persuasion battles, using the "weaponry" provided by the lecture and readings. Each battle is waged in a different task domain to provide practice in the wide range of situations in which students might use or encounter social influence. Student feedback via course evaluations and an Internet survey indicate that this learning tool is both enjoyable and enhances understanding of the material.
\end{abstract}

Because elements of persuasion and social influence are present in myriad situations that people encounter each day, these topics readily lend themselves to participative learning in an educational setting. Many educators and researchers have touted the benefits of active, rather than passive, learning (see e.g., Bonwell \& Eison, 1991; Davis, 1993; McKeachie, 2002). In addition, collaborative learning, an active learning approach in which students work in teams or small groups to master the material, has gained considerable support (Johnson, Johnson, \& Smith, 1991; Meyers, 1997; Slavin, 1980). Recently, Elias and Pratkanis (2006) compiled a review of over 50 social influence teaching activities that provide some form of active or collaborative learning. The purpose of this article is to describe an additional method of promoting student mastery of social influence principles that was developed for a business graduate student audience. These learning exercises are called Persuasion Wars.

Address correspondence to: Peggy Sue Loroz, Gonzaga University, School of Business AD 9, Spokane, WA 99258, USA. E-mail: Loroz@jepson.gonzaga.edu

I gratefully acknowledge the work of Brad Kleindl, whose consumer behavior exercises provided inspiration for the Persuasion Wars.

C 2007 Psychology Press, an imprint of the Taylor \& Francis Group, an Informa business http://www.psypress.com/socinf

DOI: $10.1080 / 15534510701279672$ 


\section{EDUCATIONAL SETTING AND BACKGROUND}

The Master's of Business Administration (MBA) program at my university is structured such that the students take two-credit courses in primary content areas (e.g., Marketing Theory and Practice, Strategic Management, Business Ethics) for the first 10 weeks of the semester, followed by one-credit electives during the last 5 weeks which typically cover specialized subject areas (e.g., Team Building, Fraud Prevention and Detection). The Persuasion Wars were developed for a one-credit elective course on persuasion. The class met one night a week for two and a half hours each session. The course had no prerequisites, so the group was comprised of 29 students from across the spectrum of MBA concentrations offered at the school (i.e., marketing, management information systems, accounting, finance, supply chain management, entrepreneurship, and ethics), as well as the joint JD-MBA program in conjunction with the law school. The students came from a variety of professional backgrounds, including investment banking, retail, engineering, and the military, and their levels of work experience ranged from part-time service sector jobs to more than 20 years of managerial experience. Given this context, I sought to develop a teaching/learning paradigm that met the following criteria:

1. It would engage students in active learning to relieve the fatigue of a lengthy class session.

2. It could be adapted to reach a fairly broad cross-section of the student population.

3. It would draw on students' varied experiences and skills to promote collaborative learning.

4. It would be interesting, memorable, and fun!

The text for the course was Influence: Science and Practice (fourth edition), by Cialdini (2001). The main content area of the course was social influence, as covered in the text, but other persuasion theories (e.g., cognitive, motivational, behavioral, affective) were presented in the lecture as well. This additional content on persuasion theory was primarily drawn from Kardes (2002), supplemented by Brock and Green (2005). Both are excellent resources for instructors teaching persuasion.

Ethical issues surrounding the use of persuasion tactics were also an important component of the course. Cialdini addresses the ethics of influence to some extent in the text, so students became aware of the ways in which social influence may be used both positively and negatively. In addition, I found it helpful to present students with the Consumer Sovereignty Test (Smith, 1995) as a tool for gauging the ethics of a given persuasion attempt. In brief, this framework requires persuaders to assess 
whether the target of a persuasive (or marketing) effort meets three criteria: (1) the target is capable of making a good decision (i.e., the target is not vulnerable due to age, education, circumstance, etc.), (2) the target has adequate information to make a good decision (i.e., substantive information has not been withheld or deceptive information provided), and (3) the target has a real choice to make (i.e., the target is not, in effect, prohibited from choosing whether to comply). Having laid this groundwork, discussions of the ethical use of influence principles became a key part of the learning paradigm as well.

Each class meeting was divided into two parts. The first 75-90 minutes of each class was spent on lecture and discussion of persuasion and ethics, including the week's reading (generally two chapters) from the Cialdini text. The last $60-75$ minutes were devoted to the Persuasion Wars.

\section{PERSUASION WARS}

The idea for Persuasion Wars came from Cialdini's use of the term "weapons of influence" throughout the text. This theme provided the impetus for developing the parameters of the learning activity, as follows. Student teams fight a persuasion battle each week, using the weaponry provided by the lecture and readings. The "battleground" (or task) for each war is determined by the instructor to be appropriate for the weapons to be used. Each battle is waged in a different task domain to provide practice in the wide range of situations in which the students might use or encounter the persuasive techniques. Novel task domains are chosen to encourage creativity and test understanding of the material, as students cannot rely on preconceived ideas of how the task should be performed (e.g., every American student knows how a car advertisement "should" look, but perhaps not an ad for a bidet!).

\section{Pre-class instructor preparations}

Materials. The instructor should prepare the Persuasion War battle plan and have a copy available for each student. (See the Appendix for sample battle plans.) It is also helpful to acquire an easel-size notepad and markers for the teams to use in preparing their materials. In addition, small prizes (perhaps theme-appropriate for each battle) may be purchased before class to award to the victors.

Team formation. Groups of four to five students are advised for collaborative learning tasks (Davis, 1993), and seems to work well for this exercise. The instructor might find it helpful to divide the students into 
teams in advance to avoid confusion and to exert control over group composition. For each war, the teams may be rotated so that everyone works with as many other students as possible, and the instructor may intentionally try to balance stronger students with weaker-performing ones, particularly toward the end of the course or unit in which the Persuasion Wars are included.

\section{Conducting the exercise}

To begin the exercise, the instructor distributes the battle plan to the class, clarifying the instructions as needed and outlining the time frame for the task. It is important to set a strict time limit (generally 25 to 30 minutes in my classes, depending on the amount of time lecture has consumed), reminding students as time draws short. The competitive nature of the exercise leads students to try to work past when time is called, which could create an unfair advantage, so monitoring this is necessary. If space allows, it is best for each team to have an area in which to discuss its strategies and assemble its materials where other teams are unable or unlikely to spy.

During the exercise, the instructor may wander from group to group, both to answer questions and to guard against loafing by any of the students. Because of the short-term nature of the group work in these tasks (i.e., groups worked together only in class and group composition changed each time), I felt that more elaborate measures to prevent free-riding were unnecessary. However, instructors may choose to address this potential problem more directly through a variety of prevention measures, including discussing the problem in class, using smaller or self-selected groups, allowing groups to "fire" group members for poor performance, and incorporating peer evaluations into course grades. (See Strong \& Anderson, 1990, for a more comprehensive discussion of these and other techniques for preventing social loafing.)

After time is called, the battle begins. Each team is randomly called to present its work, the format of which varies depending on the battle plan of the week. In this presentation, the students also briefly explain how they applied the concepts from course. This serves two purposes: (1) to ensure that they have correctly understood the material, and (2) to point out any subtleties in their usage of the concepts that other students (or the instructor!) might not have noticed. During each presentation, the other students are instructed to evaluate how persuasive they believe the influence attempt would be if they were a member of the target audience (as identified in the team's presentation). This qualification is necessary as groups may choose to tailor their strategies to an audience that is very different from a typical MBA class. In addition, students are told that this assessment of 
"persuasiveness" should include the appropriate (i.e., correct and ethical) application of the assigned persuasion techniques. During each presentation, the instructor may also wish to take notes on the target, strategy, and the concepts used by each team, and quickly generate an evaluation of the work. After each presentation, members of other groups may "attack" the strategy presented, as long as these comments and questions are couched in a theory- or concept-based framework or address the ethical nature of the persuasion attempt. A strict time limit for presentations and attack periods is advised as well.

After all teams present their work, the instructor should summarize each team's strategy in some way in order to help the class remember the content of each presentation. This may be done verbally or via an overhead created during the presentations. (Alternatively, students may be instructed to take their own notes during the presentations.) If the instructor wishes the students to participate in the evaluation process, that may also take place at this point. In my view, allowing students to have a say in the evaluations increases their interest and involvement in the other groups' presentations and facilitates learning of the material. Student input into the evaluation process may be relatively formal or more informal, depending on the preferences of the instructor, time constraints, and when the instructor desires to announce the winning team. I use a relatively informal evaluation mechanism in which each person is allowed to give one first-place vote (worth 1 point) and one second-place vote (worth $1 / 2$ point) to two different presentations. Students are not allowed to vote for their own team's work. Votes are tallied immediately, and the team with the most points is declared the winner. In my class, this team receives 25 out of 25 points possible for the assignment, as well as the prizes I have purchased. Note that in my voting instructions to the students, I do include the caveat that if I do not believe the winner of the vote to be the true winner, I reserve the right to declare an alternate winner myself. This helps to keep the students honest in their assessments and avoid "popularity contests." I have never invoked this right, as the chosen winner has always been one that reasonably could have been considered the best in the class.

Alternatively, an instructor might develop a more formal evaluation instrument that students could complete during each presentation. This might include scaled response items such as: "If you were a member of the target audience, how persuasive would you have found this presentation in convincing you to [engage in the advocated behavior]?" (with a response scale anchored by "not at all persuasive" and "very persuasive"); "How well did this team utilize [a given influence technique] in its persuasion attempt?" (with a response scale anchored by "not very well" to "very well"); and "How ethical did you perceive this persuasion attempt to be, given its target audience?" (with a response scale anchored by "very unethical" to 
"completely ethical"). The form might also include open-ended response questions such as: "How could the team have improved its use of [a given influence technique]?" or "What changes would you make to improve the persuasiveness of this strategy?" This type of peer evaluation has the advantage of directing students to more carefully evaluate each presentation and the use of course concepts, which likely aids in learning. The disadvantage is that it requires more time either inside or outside of class for students to complete the evaluation forms and for the instructor to assimilate the information and incorporate it into the evaluations. It also would make it necessary to delay announcing (and rewarding) the winner of each war, which might take away some of the competitive excitement.

\section{Post-exercise debriefing}

For instructors who are able to allocate the time, a debriefing session held either immediately after the presentations (ideally), or at the beginning of the next class period, provides an excellent way to potentially increase the educational impact of the Persuasion Wars. This time allows instructors to clarify any misunderstandings about how the influence techniques may be best used, to address any ethical concerns that may have arisen during the presentations, and to point out other noteworthy aspects of each persuasion attempt. Instructors may use their own observations on these topics to lead the discussion or prompt students to take the lead with open-ended questions. These questions may include: "After viewing all of the presentations, what changes could your team have made to better utilize [a given persuasive technique]?" or "Do you believe that any of the presentations may have 'crossed the line' in terms of what is considered ethical influence?" Students may be reluctant to discuss the negative aspects of their team's strategy (or may be eager to point out the negatives of other teams' approaches!) if they believe that the discussion will impact their evaluation, so care should be taken to alleviate this concern. For example, the scores or outcome of the war may be established before the debriefing session takes place, or the students could be assured that their participation in this part of the exercise is also a component of their grade, either for that particular war or for the class overall.

\section{Evaluation and feedback}

Depending on the manner in which the Persuasion Wars are included in students' grades, the instructor likely will want to formally evaluate all of the presentations after each class. For my classes, I rank the presentations and subtract one point for each rank position (i.e., 24 points to second place, 23 for third place, etc.). (Recall that the top ranked presentation has already been determined in class by student votes.) Although I keep the 
students' voting in mind when determining the remaining ranks, I do not strictly follow the vote totals. (If an instructor uses a more formal student evaluation mechanism, student ratings might become a percentage of an overall score.) All students on a team receive the same score. Because of the nature of the exercise and the limited time frame involved, I do not attempt to discriminate between team members, nor do I ask the students to evaluate the performance of other members of the team. I provide feedback on all of the presentations to all of the students, in the form of a class email sent later that evening or the next day while the presentations are still fresh in everyone's mind. I use this format so as to provide thorough written feedback on all of the presentations such that the students may benefit from seeing my comments on the various uses of the concepts presented in class. A secondary benefit of this feedback vehicle is that it avoids taking additional class time. An obvious drawback is that some students may choose to read only the feedback for their team's work; however, because receiving feedback only on one's own work is typical in educational settings, I am comfortable with this possibility. Another negative of the email approach is that it does not engage students in a follow-up discussion of the material after they have had practice using it themselves and have observed other teams' attempts. The aforementioned optional debriefing session would alleviate this concern.

\section{EVALUATION OF THE PERSUASION WARS EXERCISE}

The student response to the Persuasion Wars appeared to be very positive. Students clearly enjoyed both the group work and the presentations, and were quite animated during both. In addition, several students approached me before or after class to say that they really enjoyed the tasks and the competitive nature of the war format. These personal observations were bolstered by two formal evaluation mechanisms: the end-of-semester general course evaluations and an Internet survey specific to the Persuasion Wars.

\section{Course evaluations}

The standardized general course evaluations conducted on the last day of class were quite high, with students giving the course a mean rating of 6.38 (out of 7) in overall quality, with a median and mode of $7(N=26)$. As a basis of comparison, the average score for overall course quality for MBA courses taught in the same term was 5.89. In addition, the mean rating of the "pertinence of assignments/activities" item was 6.29 , also with a median and mode of 7, as compared to the average score of 5.99 across all MBA courses that term. Because the Persuasion Wars were the only assignments or 
activities in this one-credit course, this rating should reflect student evaluations of this learning exercise.

\section{Internet survey}

Approximately 9 months after the course ended, all of the students received an e-mail requesting their participation in an on-line survey evaluating the Persuasion Wars exercise. No incentive was offered for participation, and all responses were anonymous. Of the 29 students, 21 responded to this request, a response rate of $72 \%$. (Note that 10 of the students had graduated within that time, and some may no longer have been checking their university e-mail accounts.) Items comprising this survey are included in Table 1 . The first 10 items asked students to respond on a 5-point scale with the following response categories: $1=$ strongly disagree, $2=$ disagree, $3=$ neither agree nor disagree, $4=$ agree, and $5=$ strongly agree. Each of these items was subjected to a one-sample, two-tailed $t$-test with 3 as the test value. Means of all of the items were significantly higher than the neutral value of 3 (all $p$ s $<.001$ ), as shown in Table 1. In fact, the means of all but one item (item 9) were significantly greater than a test value of 4 (all $p$ s $<.01$ ), indicating that, overall, the respondents felt strongly that the Persuasion Wars were both useful for learning and enjoyable.

TABLE 1

Items comprising the Internet survey

\begin{tabular}{|c|c|c|c|c|}
\hline Item & Mean* & $S D$ & $t$ & $p$ \\
\hline $\begin{array}{l}\text { 1. By participating in the Persuasion Wars, I gained a better } \\
\text { understanding of persuasion theories and social influence. }\end{array}$ & 4.52 & 602 & 11.608 & .000 \\
\hline $\begin{array}{l}\text { 2. The Persuasion Wars provided me an opportunity to } \\
\text { work cooperatively with other members of the class. }\end{array}$ & 4.90 & .301 & 29.019 & .000 \\
\hline $\begin{array}{l}\text { 3. The Persuasion Wars helped me understand the related } \\
\text { text and lecture material. }\end{array}$ & 4.62 & .498 & 14.910 & .000 \\
\hline 4. The Persuasion Wars were enjoyable. & 4.71 & 463 & 16.971 & .000 \\
\hline 5. The Persuasion Wars were interesting. & 4.76 & .436 & 18.500 & .000 \\
\hline 6. The Persuasion Wars were informative. & 4.43 & .598 & 10.954 & .000 \\
\hline $\begin{array}{l}\text { 7. The Persuasion Wars should be included in future } \\
\text { sections of the course. }\end{array}$ & 4.81 & 402 & 20.608 & .000 \\
\hline $\begin{array}{l}\text { 8. I liked participating in the Persuasion Wars as a way to } \\
\text { learn about persuasion and social influence. }\end{array}$ & 4.48 & .602 & 11.245 & .000 \\
\hline $\begin{array}{l}\text { 9. The Persuasion Wars were helpful in revealing how } \\
\text { I might be vulnerable to persuasion and social influence. }\end{array}$ & 4.24 & .768 & 7.384 & .000 \\
\hline $\begin{array}{l}\text { 10. The Persuasion Wars were helpful in understanding } \\
\text { how I might use persuasion and social influence. }\end{array}$ & 4.76 & .539 & 14.981 & .000 \\
\hline
\end{tabular}

Results of Internet survey $t$-tests (test value $=3$ ). ${ }^{*}$ Responses on a scale of $1-5$, anchored by $1=$ "strongly disagree" and 5="strongly agree". 
The final item was an open-ended question: "If you have any other comments on the Persuasion Wars as a learning tool, please feel free to share them below." A total of 13 students chose to respond, and the comments were generally very positive. The following three excerpts were typical of the whole:

I believe the Persuasion Wars were not only an interesting and enjoyable activity but highly relevant to the course learning objectives. They were essential in practicing and reinforcing the concepts that were discussed in the readings and lecture.

The structure of the Persuasion Wars challenged students to be creative and competitive ... and provided students with a variety of different learning opportunities and challenged us to be 'on our game' at all times.

[The Persuasion Wars] allowed me to work with a new group every time and learn from different backgrounds to develop new ideas based on their career experience.

Although there is no way to know the extent of non-response bias (eight students did not respond to the survey), it seems clear that the majority of the students felt that the exercise did achieve the goal I had in mind, i.e., developing an exercise that is engaging, draws on the diverse experiences of the student body, and helps students learn to apply the material.

\section{DISCUSSION AND CONCLUSION}

A couple of aspects of this learning paradigm do present challenges. First, if a student misses a class session there is no way to really "make up" a Persuasion War. Although attendance in a 5-week course is essentially mandatory, a few MBA students inevitably have work obligations that interfere with their attendance. In these cases, it is possible to give a written version of the task and grade it individually, but the experience is not quite the same. Second, there is the potential problem of group, as opposed to individual, evaluation. MBA students are generally accustomed to working in teams, so I have received no complaints about this practice; however, undergraduate students may be concerned with the fairness of this approach. The in-class work time and the nature of the Persuasion War tasks help to alleviate some of the problems (e.g., loafing by some team members) that lead students to desire more discriminative grading practices.

In conclusion, Persuasion Wars take advantage of the inherent benefits of active and collaborative learning. They engage students in the material in a 
manner that is fun and interesting but also provides the instructor with immediate feedback on their understanding of course concepts. Furthermore, the battlegrounds may include a variety of contexts or may be tailored to reach students with specific backgrounds and experiences. Although this learning activity was developed with MBA students in mind, and takes advantage of their comfort with teamwork, their competitive natures, and their broad professional experiences, it could easily be adapted for use with other audiences, including undergraduate students in psychology. Persuasion Wars are appropriate for courses that focus on persuasion, or may be included as part of the persuasion unit of a broader course such as Social Psychology, Consumer Psychology, Consumer Behavior, Organization Behavior, or Sales and Marketing.

Manuscript received 9 October 2006 Manuscript accepted 12 February 2007

\section{REFERENCES}

Bonwell, C. C., \& Eison, J. A. (1991). Active learning: Creating excitement in the classroom [ASHE-ERIC Higher Education Report No. 1]. Washington, DC: George Washington University.

Brock, T. C., \& Green M. C. (Eds). (2005). Persuasion: Psychological insights and perspectives (2nd ed.). Thousand Oaks, CA: Sage.

Chaiken, S. (1987). The heuristic model of persuasion. In M. Zanna, J. Olson \& C. Herman (Eds.), Social influence: The Ontario symposium (Vol. 5, pp. 3-40). Hillsdale, NJ: Erlbaum.

Cialdini, R. B. (2001). Influence: Science and practice (4th ed.). Needham Heights, MA: Allyn \& Bacon.

Davis, B. G. (1993). Tools for teaching. San Francisco: Jossey-Bass Publishers.

Elias, S. M., \& Pratkanis, A. R. (2006). Teaching social influence: Demonstrations and exercises from the discipline of social psychology. Social Influence, 1 (2), 147-162.

Johnson, D. W., Johnson, R. T., \& Smith, K. A. (1991). Cooperative learning: Increasing college faculty instructional productivity ASHE-ERIC Higher Education Report No. 4. Washington, DC: George Washington University.

Kardes, F. R. (2002). Consumer behavior and managerial decision making (2nd ed.). Upper Saddle River, NJ: Prentice Hall.

McKeachie, W. J. (2002). McKeachie's teaching tips: Strategies, research, and theory for college and university teachers. Boston, MA: Houghton Mifflin.

Meyers, S. A. (1997). Increasing student participation and productivity in small-group activities for psychology classes. Teaching of Psychology, 24, 105-115.

Petty, R. E., \& Cacioppo, J. T. (1986). The elaboration likelihood model of persuasion. In L. Berkovitz (Ed.), Advances in experimental social psychology (Vol. 19, pp. 123-205). New York: Academic Press.

Slavin, R. F. (1980). Cooperative learning. Review of Educational Research, 50 (2), 315-342.

Smith, N. C. (1995). Marketing strategies for the ethics era. Sloan Management Review, 36 (4), 85-97.

Strong, J. T., \& Anderson, R. E. (1990). Free-riding in group projects: Control mechanisms and preliminary data. Journal of Marketing Education, 12 (2), 61-67. 


\section{APPENDIX: PERSUASION WAR BATTLE PLANS}

\section{Persuasion War I}

Your task is to use the dual process models of persuasion (i.e., the HeuristicSystematic Model and the Elaboration Likelihood Model) presented in the lecture and in Chapter 1 of your text to develop two print advertisements (including visuals and copy) to sell some form of bidet to an American target market. One ad should be appropriate for systematic/central route processing; the other should be designed for heuristic/peripheral route processing. Both ads should be reasonable to include as part of a single ad campaign.

In your presentation, you must:

1. Identify the specific target market(s) for the ads (quick profile, don't be afraid to be narrow!).

2. Name the specific product/brand/company for which your ads were developed (real or imaginary).

3. Pitch your ad executions to your client (played by the class), explicitly using concepts covered in the course this evening. The presentation should be persuasive as well as provide evidence of your understanding of the material.

Note: The instructor is referred to Chaiken (1987) and Petty and Cacioppo (1986) for additional background on the Heuristic-Systematic and Elaboration Likelihood Models, respectively.

\section{Persuasion War II}

You work for a non-profit whose mission is to increase cadaver donations. Your task is to use the concepts of Reciprocity and/or Commitment and Consistency (presented in Chapters 2 and 3 of your text) to develop a strategy or strategies to persuade members of an organization of your choosing to become body donors after they die. This strategy may NOT rely solely on traditional advertising. Consider other, more effective mediums for convincing your target market to agree to do this (e.g., a "sales" presentation of some sort, an event, etc.) and explain how you would implement it (including relevant persuasive details).

In your presentation, you must:

1. Identify the specific organization you will be targeting and why (don't be afraid to be narrow!). 
And do either (or both, your choice) of the following:

(a) Pitch your strategies to the class, and WHY you think they will be effective (based on the concepts we've discussed in class so far). The presentation should be persuasive as well as provide evidence of your understanding of the material.

(b) Engage the class as if we were members of the target organization and try your strategy on us!

\section{Persuasion War III}

One member of your group is going to run for office, specifically to be the first President of the Graduate Student Body at this university. Your task is to use the concepts of Scarcity and/or Social Proof (presented in Chapters 7 and 4 of your text) to develop a campaign strategy to persuade graduate students to vote for your candidate. You may choose to develop a "platform" for your candidate if you wish; however, victory in the war will not be judged on the "issues" but rather on the persuasiveness of the campaign. Therefore, please feel free to have fun with this in brainstorming about how to implement the concepts. Material for campaign posters is available, if you wish to use them.

During your presentation time:

1. You will hold a short (no more than 5 minutes) campaign rally in which your candidate and others may make speeches or otherwise engage the crowd in a persuasive manner.

2. Before or after this "rally" you may explain your campaign and rally strategies to the class, and WHY you think they will be effective.

\section{Persuasion War IV}

Your task is to use the Liking Principle and/or the Authority Principle (presented in Chapters 5 and 6 of your text) to develop a television ad to sell a body waxing service (offered by an existing or an imaginary company) to any male target market. You will be "acting out" this ad for the class. You may use the poster paper/markers to create additional visuals if you wish.

In your presentation, you must:

1. Identify the specific target market or markets for the ads (quick profile, don't be afraid to be narrow!).

2. Give us any background or set-up information necessary to understand your ad.

3. Act out the ad for the class. 
4. Offer closing comments in which you pitch your advertising strategy to the class, and WHY you think it will be effective (based on the concepts we've discussed in class). The presentation should be persuasive as well as provide evidence of your understanding of the material. 
Copyright of Social Influence is the property of Psychology Press (UK) and its content may not be copied or emailed to multiple sites or posted to a listserv without the copyright holder's express written permission. However, users may print, download, or email articles for individual use. 